No. $17-5$

\title{
Sectoral Inflation and the Phillips Curve: What Has Changed since the Great Recession?
}

\section{María José Luengo-Prado, Nikhil Rao, and Viacheslav Sheremirov}

\begin{abstract}
:
Using sectoral data at a medium level of aggregation, we find that price changes became less responsive to aggregate unemployment around 2009-2010. The slopes of the disaggregated Phillips curves diminished in many sectors, including housing and some services. We also document a decrease in sectoral inflation persistence, suggesting an increase in the weight of the forward-looking inflation expectation component and a decrease in the weight of the backward-looking component.
\end{abstract}

Keywords: disaggregate price indices, inflation persistence, Phillips curve JEL Classification: E24, E31, E32

María José Luengo-Prado is a senior economist and policy advisor in the research department of the Federal Reserve Bank of Boston. Nikhil Rao is a senior research assistant in the research department of the Federal Reserve Bank of Boston. Viacheslav Sheremirov is an economist in the research department of the Federal Reserve Bank of Boston. Their email addresses are Maria.Luengo-Prado@bos.frb.org, Nikhil.Rao@bos.frb.org, and Viacheslav.Sheremirov@bos.frb.org, respectively.

We are grateful to Michelle Barnes, Falk Bräuning, Daniel Cooper, José Fillat, Jeff Fuhrer, Chris Foote, Giovanni Olivei, Ali Ozdagli, Joe Peek, Eric Rosengren, Jenny Tang, and Geoff Tootell for insightful comments. Katrina Truebenbach helped us understand disaggregated employment data, and Chloe Lee provided superb research assistance. We also thank Lawrence Bean for excellent editorial assistance.

This paper, which may be revised, is available on the website of the Federal Reserve Bank of Boston at http://www.bostonfed.org/economic/current-policy-perspectives/index.htm.

The views expressed in this paper are those of the author and do not necessarily represent the views of the Federal Reserve Bank of Boston or the Federal Reserve System.

This version: November 2017 


\section{Introduction}

Policymakers have struggled recently to understand why inflation dynamics differ from the predictions of workhorse models. One of the pillars of such models, the aggregate Phillips curve, predicts that as the labor market tightens, prices eventually face an upward pressure, and inflation takes off. Yet, while the unemployment rate decreased from a peak of 9.9 percent in the fourth quarter of 2009 to 4.3 percent in the third quarter of 2017, core inflation remained stubbornly below the Federal Open Market Committee (FOMC) target of 2 percent.

This stark deviation from the norm has led some economists to believe that the aggregate Phillips curve is no longer a useful model for policy analysis. Proponents of this view suggest that researchers and policymakers look at inflation data per se-and not through the lens of a particular model. ${ }^{1}$ Many others, though, continue to believe the Phillips curve remains informative, and that the recent changes in inflation dynamics can be reconciled with the models by allowing for a structural break in model parameters. ${ }^{2}$

In this policy brief, we study disaggregated inflation data to understand whether a sectoral Phillips curve can shed light on changing inflation dynamics. Sectoral data provide rich variation in disaggregated inflation rates within and between sectors and allow us to single out the sectors that may have contributed the most to a possible break. This approach also addresses the Phillips curve doubters' recommendations to more closely consider individual inflation series. For example, we can study univariate inflation persistence at the sectoral level. It also allows us to investigate the role of transitory sectoral shocks, some of which have recently been brought to the forefront of inflation debates (such as price wars in the mobile communication sector; see Yellen 2017).

Using sectoral consumer price index (CPI) data from the Bureau of Labor Statistics (BLS) at a medium level of disaggregation, we find robust evidence of a structural break in the Phillips curve slope around 2009-2010. The co-movement of sectoral inflation rates and labor market slack has weakened, and it is now almost negligible. This change occurred broadly across sectors, although some sectors, including housing and certain services such as food away from home, stand out in a statistical sense. We also use univariate time-series techniques to document a decline in inflation persistence in many sectors. With the help of a theoretical model, we further derive structural parameters of a hybrid (sectoral) Phillips curve and document a decrease in the relative weight of inflation lags and an increase in the relative weight of the forward-looking expectation component. Taken together, our findings imply that low inflation today may tell us less about (low) inflation tomorrow than suggested by estimates in previous studies.

To conduct our analysis, we compiled a list of disaggregated CPI sectors that are neither too large

\footnotetext{
${ }^{1}$ For example, the Economist of November 1, 2017, highlights this debate in its daily chart; see economist.com/blogs/graphicdetail/2017/11/daily-chart. Also, Miles et al. (2017) study different theories of inflation and interpret them in the context of the Great Recession. Those authors believe that in terms of inflation over the past 10 years, we were lucky. However, they see below-target inflation with low policy rates as a source of worry if this implies that, when the next recession hits, policymakers have less room to lower real interest rates.

${ }^{2}$ The structural break may pertain to the slope of the Phillips curve (a change in inflation-unemployment comovement), the natural rate of unemployment, the relative weights of forward-looking and backward-looking expectation components, etc.
} 
to have a disproportionate effect on aggregate results nor too small to be negligible for aggregate dynamics (and less likely to exhibit highly transitory effects). This selection was made with a market definition in mind. Whenever possible, we focus on sectors with goods sold at a particular type of retailer (for instance, food at home is sold in grocery stores). We study 16 sectors with relative weights ranging from 2 percent to 8 percent, except the larger "Owners' Equivalent Rent" sector, covering almost 95 percent of the CPI.

We focus on CPI data for several reasons. First, a large body of academic literature studying Phillips curves uses headline CPI as the benchmark measure of inflation. ${ }^{3}$ Also, many findings are robust to the inflation measure used, and many studies switch relatively seamlessly between the CPI (core or headline), the personal consumption expenditures (PCE) price index, and the gross domestic product (GDP) deflator. ${ }^{4}$ Second, inflation has been consistently low recently regardless of the index used, and the change in the slope of the aggregate Phillips curve is not confined to a specific measure. Finally, a major difference between the CPI and the PCE price index is due to component weights. Because we conduct our analysis at a disaggregated level—and present results for each sector individually-differences in weights may be less of an issue. Nonetheless, the disaggregated categories in the PCE data are different, and it may be worth exploring this in future work.

Our results have broad implications for economic models and monetary policy. On the theory side, a structural break in key reduced-form parameters of the Phillips curve calls for a search of the break's origin in terms of micro-founded structural parameters. On the policy side, a Phillips curve flattening implies a slower response of inflation to policy tools, potentially requiring an adjustment of the policy-rate path obtained from historical observations. Next, decreasing persistence implies that low inflation in the past may not necessarily be indicative of low inflation in the future, and that managing expectations should play a crucial role in policy decisions. In our framework, low inflation may come directly from expectations of low inflation in the future or indirectly from expectations of policies leading to more slack in labor markets going forward. It is important to be cautious about conclusions based on historical data, as more work is needed to understand the sources and longevity of the identified break. Sectoral data, however, point to broad changes across sectors: the results are not confined to a handful of sectors affected by global trends in tradeable goods prices or downward pressure from internet prices.

This paper proceeds as follows: Section 2 describes the disaggregated CPI categories selected for our analysis and their recent inflation dynamics. In Section 3, we show that there is robust evidence of a flattening of the Phillips curve around 2009-2010, stemming from a broad range of categories. We then zoom in on the recent post-recession period to identify the categories that contributed the most to the break. In Section 4, we focus on inflation persistence. We explore a univariate timeseries model of inflation, as well as a hybrid New Keynesian Phillips curve model that illustrates the

\footnotetext{
${ }^{3}$ Coibion, Gorodnichenko, and Kamdar (2017) provide a comprehensive overview of the literature estimating Phillips curves.

${ }^{4}$ One exception is documented in Doser, Nunes, Rao, and Sheremirov (2017): the nonlinearities of the aggregate Phillips curve appear more pronounced for the PCE price index and the GDP deflator than for the CPI. One potential explanation is that survey consumer expectations are more representative of the CPI than of alternative inflation measures.
} 
Figure 1. Disaggregated Inflation Rates: Level I Categories
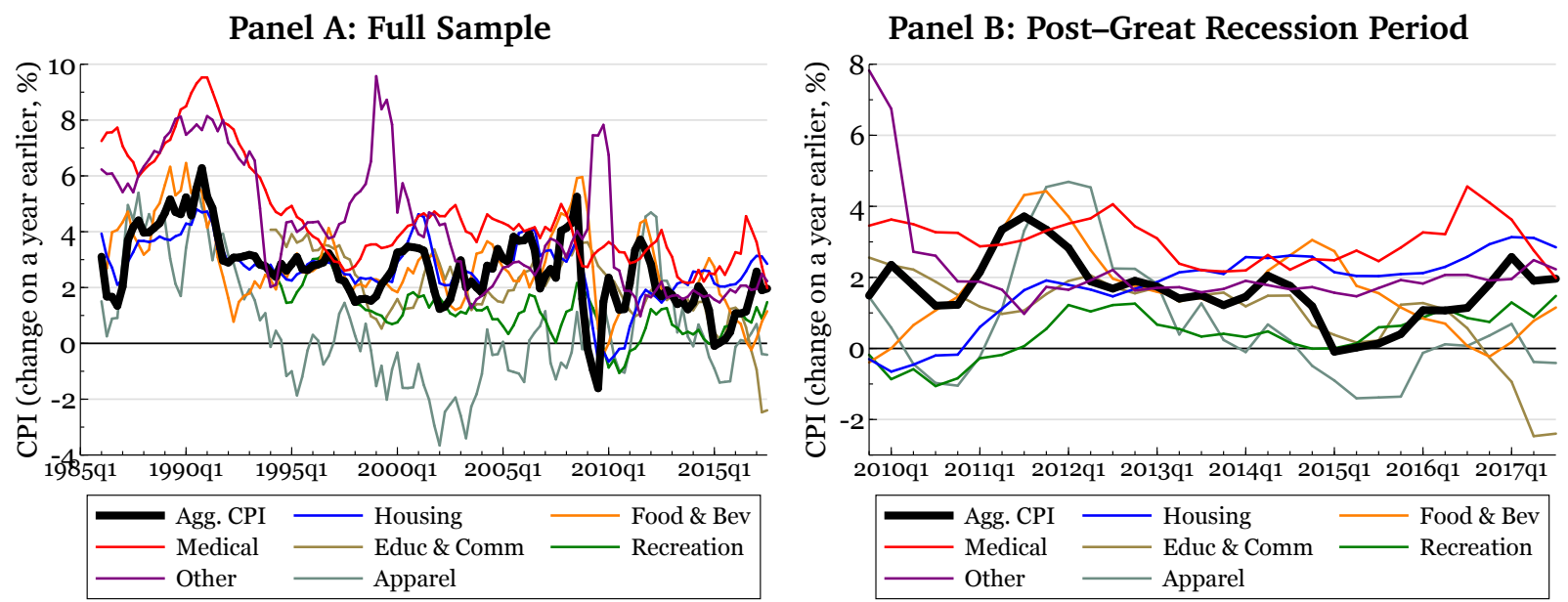

Source: BLS.

Notes: To enhance visibility, "Transportation" is excluded from the graph. See Figure A1 in Appendix A for all categories.

relationship between our reduced-form estimates and structural parameters. This exercise enables us to derive the relative weights of the forward-looking and backward-looking inflation expectation components. Section 5 concludes.

\section{Disaggregated CPI Data}

\section{$2.1 \quad$ Level I Categories}

Let us describe how the BLS aggregates CPI data across categories. The Level I disaggregation comprises eight categories (the weights as of $2017 q 3$ are in parentheses): ${ }^{5}$

- Housing (42.6\%),

- Transportation (15.3\%),

- Food and Beverages (14.6\%),

- Medical Care (8.5\%),

- Education and Communication (7.0\%),

- Recreation (5.7\%),

- Other Goods and Services (3.2\%; mostly personal-care products),

- Apparel (3.0\%).

Panel A of Figure 1 shows disaggregated quarterly inflation rates, computed as the change in the seasonally adjusted index since the previous year, for Level I categories from 1986q1 to 2017q3. In the full sample, the volatility of the disaggregated inflation rates exceeds that of aggregate inflation. Also, individual trends do not always follow the aggregate CPI. For example, in the late 1990s,

\footnotetext{
${ }^{5}$ Weights add up to 99.9 percent due to a rounding error.
} 
Table 1. An Example of Selecting Disaggregated Categories: "Food and Beverages" vs. "Apparel”

- Food and Beverages (14.6\%)

- Food (13.7\%)

Food at Home (7.9\%)

$\square$ Food Away from Home (5.7\%)

- Alcoholic Beverages (1.0\%)
- Apparel (3.0\%)

- Women's and Girls' (1.2\%)

- Men's and Boys' (0.8\%)

- Footwear (0.7\%)

- Infants' and Toddlers' $(0.2 \%)$

- Jewelry and Watches $(0.2 \%)$

Source: BLS.

Notes: The table provides an example of selection across Level I, Level II, and Level III BLS categories. Selected categories are in boldface and a dropped category is struck out. Current weights are in parentheses.

personal-care products ("Other Goods and Services") trended up, while "Apparel" trended down. These are useful properties for determining which sectors may have contributed the most to recent changes in aggregate inflation properties.

Panel B of Figure 1 magnifies the period after the Great Recession (starting from 2009q4). "Education and Communication" exhibited a downward inflation trend from 2016q1 to 2017q3. "Apparel" showed decreasing prices in most quarters after 2014q1. As Panel A shows, this sector had low relative prices and frequent episodes of decreasing prices for most of the sample period, but its share in the aggregate CPI is rather low. The "Food and Beverages" series also trended down starting in early 2015. In contrast, "Housing," "Recreation," and "Other" (personal care) had stable inflation rates recently, while "Medical Care" inflation rose until mid-2016 and then decreased somewhat.

\subsection{Selecting the Disaggregation Level}

Level I categories can be informative about recent trends in disaggregated inflation, but it is problematic to estimate a sectoral Phillips curve at such a high level of aggregation. Regressions with CPI weights are dominated by only a few series, including "Housing" and "Transportation" (and the latter has high transitory volatility due to oil price fluctuations). Unweighted regressions instead assign equal weights to all eight sectors, amplifying relationships pertinent to small sectors such as "Apparel" or "Other." Unweighted results may also be hard to reconcile with those from aggregate CPI regressions. We therefore conduct our analysis at a lower level of aggregation. We compile a list of sectors that satisfy the following criteria: (i) a size that is not too large and not too small; (ii) reasonable homogeneity in the size distribution; and (iii) a definition that roughly corresponds to a market perception.

Off-the-shelf Level II or Level III BLS categories do not meet these criteria. To understand the principle used to select an appropriate level of aggregation, consider "Food and Beverages" and "Apparel" (Table 1). Products in Level III categories "Food at Home" and "Food Away from Home" are sold in different markets (grocery stores vs. restaurants) and represent a relatively equal split of "Food and Beverages." The Level II category "Alcoholic Beverages" is too small to affect the aggregate CPI in a material way, and therefore we drop it from the analysis. In contrast, the Level I category "Apparel" already has a small weight and comprises Level II categories that do not rep- 
Figure 2. Disaggregated Inflation Rates: Categories Selected for Our Analysis
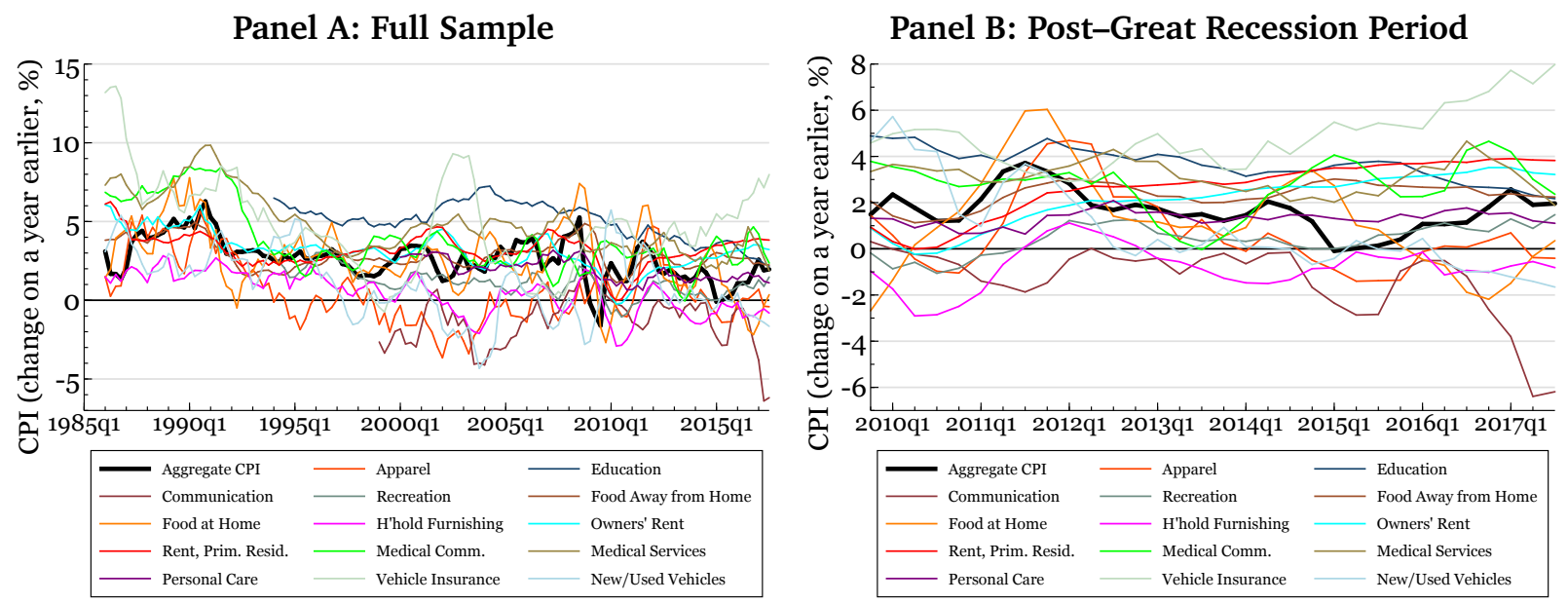

Source: BLS.

Note: To enhance visibility, "Motor Fuel" (Transportation) and "Fuels and Utilities" (Housing) are excluded from the graph (but included in our analysis).

resent different markets. For example, "Women's and Girls' Apparel," "Men's and Boys' Apparel," and "Footwear" are often sold at the same stores. Therefore, we do not split "Apparel" into more disaggregated categories.

We compose a list of 16 categories comprising seven Level III BLS categories, seven Level II categories, and two Level I categories. These 16 categories cover 94.1 percent of the CPI. The full list of categories with their 2017 CPI weights is presented in Appendix B. Each category has an individual CPI weight in the range of 2 percent to 8 percent, with one important exception: "Owners' Equivalent Rent of Residence," which has a weight of 24.6 percent. Imputed rents can be further split into only the rents of primary and secondary residences. However, the largest component of this index, rent of primary residence, is dominant, and therefore we do not split this category further. Unfortunately, publicly available BLS data do not allow us to create separate indices based on the type of housing (such as luxury city apartments vs. suburban houses).

Panel A of Figure 2 depicts inflation dynamics during our sample period for the selected categories. These categories exhibit even more time dispersion than do Level I categories, and they provide a rich source of variation to study their co-movement with economic slack. Panel B again zooms in on the most recent period. When describing Figure 1, we focused on three sectors that contributed to the low inflation rates in the recent period: "Education and Communication," "Food," and "Apparel." Now, we can narrow the source further. "Communication"-when separated from "Education"- appears to be a particularly forceful source. The downward trend in "Food" comes entirely from "Food at Home" (goods); inflation of "Food Away from Home" is stable and above 2 percent. The prices for "New and Used Vehicles" exhibit a downward trend, falling in 2016 and 2017. The prices for "Household Furnishings and Operations" are also falling. Overall, our classification reveals more clear trends than those uncovered by the more aggregated Level I classification. 


\section{Structural Break in Sectoral Phillips Curves}

To test for a structural break in the Phillips curve slope using sectoral data, we estimate the following model:

$$
\pi_{j t}=\mu_{j}+\widetilde{\mu}_{j} \mathbb{1}_{t>\tau}+\sum_{i=1}^{5} \alpha_{i} \pi_{j, t-i}+\beta u_{t}+\widetilde{\beta} \mathbb{1}_{t>\tau} u_{t}+\gamma Z_{j t}+\varepsilon_{j t},
$$

where $\pi_{j t}$ is sector $j$ inflation in quarter $t$; $u_{t}$ is the aggregate unemployment gap with the natural rate estimated by the Congressional Budget Office (CBO); $Z_{j t}$ is a vector of controls, which includes the percentage change in the oil price in the baseline, as well as some sector-specific controls in robustness exercises; $\mathbb{1}_{t>\tau}$ is an indicator function for a period after a structural break $\tau$; $\varepsilon_{j t}$ is the error term; and the rest are parameters to be estimated. It is essential that we allow for sectoral fixed effects $\mu_{j}$ to account for differences in productivity levels across industries, which may lead to different levels of steady-state inflation. ${ }^{6}$ The test results, however, are robust to excluding the intercept break or allowing for the effect of oil-price changes to vary by sector.

This model is estimated for a range of possible structural breaks $\tau$. For each $\tau$, the structural break test computes an $F$-statistic for a null hypothesis $\widetilde{\beta}=0$ (no structural break). The identified break $\tau^{*}$ is chosen to maximize the $F$-statistic of this test. The statistical significance of the break is determined by comparing $F\left(\tau^{*}\right)$ with the test's critical values.

Panel A of Figure 3 shows the $F$-statistic of the test across possible structural breaks (the horizontal red line indicates a 5 percent critical value). The test picks 2010q3 as a structural break, but the $F$-statistic is elevated throughout the Great Recession. When we drop highly volatile categories such as "Motor Fuel" and "Fuels and Utilities" or keep only core CPI categories, the break estimate occurs just one quarter later, 2010q4 (Appendix Figure A2).

One could worry that the unemployment-gap data are revised at low frequencies. If the measure of the gap is better at the left end of the sample period than it is at the right end, a structural break may be due to measurement error in the gap. Indeed, a classical measurement error in the righthand side variable leads to attenuation bias, which could produce spurious flattening. Although we cannot access revised CBO data before they are actually revised, we can use a real-time gap measure, which is consistent throughout the entire sample (Appendix Figure A3). The real-time measure is likely less informative about economic slack than a revised measure, so the point of this exercise is only to determine whether revisions contributed to the statistical identification of the break. Appendix Figure A4 shows that the structural break is identified around 2010q3 for a specification that uses the real-time unemployment gap (Panel A), and for a specification with the unemployment rate as the driving variable (Panel B). We conclude that revisions in the gap did not play a major role in our results. ${ }^{7}$

\footnotetext{
${ }^{6}$ In the baseline, we allow for a structural break in the intercept at the sectoral level, which accounts for possibly divergent productivity trends across sectors, as well as-in part-for the absence of sectoral measures of forward-looking inflation expectations. Also, the change in the price of oil is the only control included in our baseline specification.

${ }^{7}$ This analysis does not rule out the possibility that a revised unemployment gap series in the future may change the results. In the past, however, revisions have not been large enough to affect conclusions regarding (past) structural breaks.
} 
Figure 3. Structural Break Test

Panel A: Panel Regression, $F$-statistic

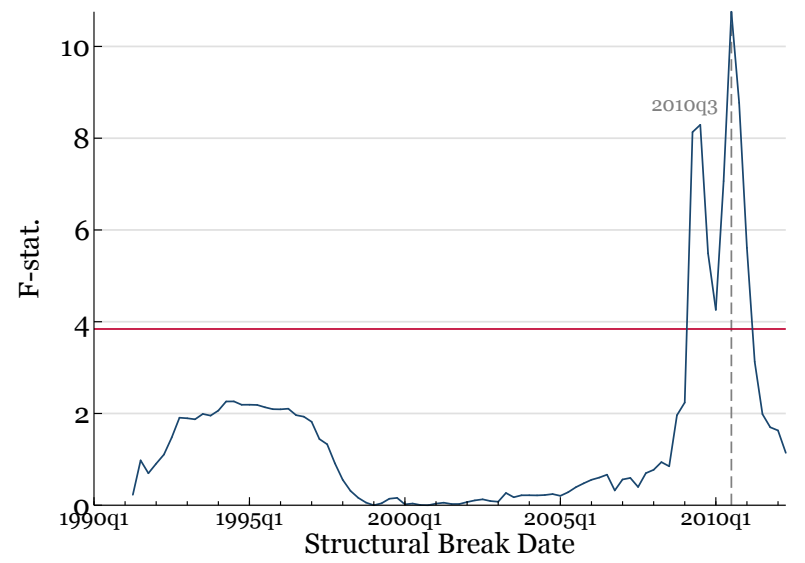

Panel B: By Category, $p$-values

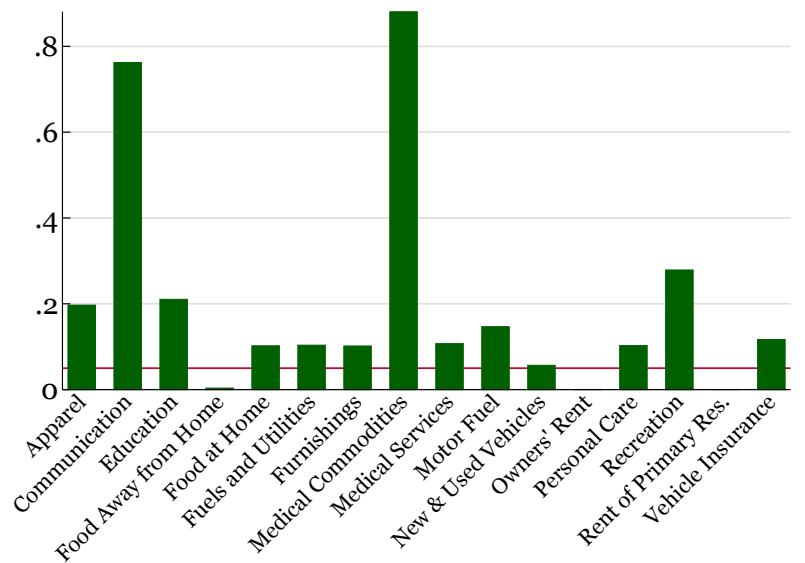

Source: Authors' calculations.

Notes: Panel A shows the $F$-statistic (vertical axis) from the test that the change in the unemployment gap coefficient is zero for a range of potential break points (horizontal axis) obtained from panel regressions of sectors. High values of $F$ indicate a change. Panel B shows $p$-values for a similar test run for each sector separately and a break date that maximizes the $F$-statistic in the left panel (2010q3). Sample period: 1986q1-2017q3. Dependent variable: the change in the quarterly seasonally adjusted sectoral CPI from the previous year. Controls: sectoral fixed effects, five lags of dependent variable, percentage change in the price of oil. The left panel allows for a break in the sectoral fixed effect and applies sectoral weights. Newey-West standard errors are used to calculate $p$-values. The horizonal red lines correspond to a 5 percent significance level.

We also estimate a version of this model controlling for five lags of aggregate inflation (Panel C of Appendix Figure A4). Aggregate inflation may help better capture expectations about future inflation. It also may address a relative-price interpretation of sectoral indices. As the figure shows, this specification yields a familiar break. In the baseline specification, the sum of sectoral inflation lag coefficients is around 0.7. With the lags of aggregate inflation, this sum is almost unchanged, while the sum of the aggregate inflation lag coefficients is 0.1. Adding aggregate inflation expectations from the Michigan Survey of Consumers (MSC) does not have a material effect on these coefficients and, if anything, pushes the sum of coefficients on the lags of aggregate inflation closer to zero. Controlling for changes in relative prices directly in the panel regressions by including five lags of (the log of) the sector specific price index relative to the aggregate CPI (Panel D of Appendix Figure A4) does not alter our conclusions either. If anything, the structural change is better identified and occurs a bit earlier, around 2009q3. Testing for a structural break involves trimming the sample from both ends. The baseline test is based on trimming five years of data. Alternative strategies, such as trimming only two years of data (Panel E of Appendix Figure A4), point to similar estimates of the break.

Which sectors contributed the most to the structural break in the Phillips curve slope in 2010? To answer this question, we estimate Equation (1) for each sector $j$ separately using $\tau^{*}=2010 q 3$ as the structural break date (as identified from the panel regression). ${ }^{8}$ Note that whereas in the baseline panel setup all parameters except the fixed effects are the same across sectors, in this exercise all

\footnotetext{
${ }^{8}$ To conserve degrees of freedom in time-series specifications, we allow for a break only in the slope (and not in the intercept). This modeling choice does not have a material effect on our conclusions.
} 
Table 2. Structural Break Tests: Slopes of Sectoral Phillips Curve

\begin{tabular}{|c|c|c|c|}
\hline & $\begin{array}{c}\text { Slope before } \\
2010 q 3, \beta_{j} \\
\text { (1) }\end{array}$ & $\begin{array}{l}\text { Change in } \\
\text { slope, } \widetilde{\beta}_{j} \\
\text { (2) }\end{array}$ & $\begin{array}{c}\text { Obs., } \\
N \\
(3)\end{array}$ \\
\hline \multicolumn{4}{|c|}{ Panel A: Sector-Specific Slopes from Time-Series Regressions } \\
\hline Apparel & $\begin{array}{c}-0.017 \\
(0.046)\end{array}$ & $\begin{array}{c}0.127 \\
(0.098)\end{array}$ & 122 \\
\hline Education & $\begin{array}{c}-0.028^{* *} \\
(0.012)\end{array}$ & $\begin{array}{c}0.025 \\
(0.020)\end{array}$ & 90 \\
\hline Communication & $\begin{array}{c}-0.011 \\
(0.079)\end{array}$ & $\begin{array}{c}0.019 \\
(0.062)\end{array}$ & 70 \\
\hline Recreation & $\begin{array}{c}-0.061^{* *} \\
(0.024)\end{array}$ & $\begin{array}{c}0.030 \\
(0.027)\end{array}$ & 90 \\
\hline Food Away from Home & $\begin{array}{c}-0.071^{* * *} \\
(0.018)\end{array}$ & $\begin{array}{l}0.065^{* * *} \\
(0.022)\end{array}$ & 122 \\
\hline Food at Home & $\begin{array}{c}-0.171^{* *} \\
(0.074)\end{array}$ & $\begin{array}{c}0.190 \\
(0.115)\end{array}$ & 122 \\
\hline Fuels and Utilities & $\begin{array}{c}-0.290^{* *} \\
(0.139)\end{array}$ & $\begin{array}{c}0.264 \\
(0.161)\end{array}$ & 122 \\
\hline Household Furnishings and Operations & $\begin{array}{c}-0.077^{* * *} \\
(0.026)\end{array}$ & $\begin{array}{c}0.082 \\
(0.050)\end{array}$ & 122 \\
\hline Owners' Equivalent Rent & $\begin{array}{l}-0.105^{* * *} \\
(0.022)\end{array}$ & $\begin{array}{l}0.109^{* * *} \\
(0.026)\end{array}$ & 122 \\
\hline Rent of Primary Residence & $\begin{array}{c}-0.125^{* * *} \\
(0.016)\end{array}$ & $\begin{array}{l}0.109^{* * *} \\
(0.019)\end{array}$ & 122 \\
\hline Medical Commodities & $\begin{array}{c}-0.025 \\
(0.040)\end{array}$ & $\begin{array}{c}-0.008 \\
(0.053)\end{array}$ & 122 \\
\hline Medical Services & $\begin{array}{c}-0.053^{* *} \\
(0.023)\end{array}$ & $\begin{array}{c}0.052 \\
(0.032)\end{array}$ & 122 \\
\hline Personal Care & $\begin{array}{l}-0.103^{* * *} \\
(0.022)\end{array}$ & $\begin{array}{c}0.075 \\
(0.045)\end{array}$ & 66 \\
\hline Motor Fuel & $\begin{array}{c}-0.957 \\
(0.725)\end{array}$ & $\begin{array}{c}2.025 \\
(1.386)\end{array}$ & 122 \\
\hline Vehicle Insurance & $\begin{array}{c}0.030 \\
(0.030)\end{array}$ & $\begin{array}{c}-0.056 \\
(0.036)\end{array}$ & 122 \\
\hline New and Used Vehicles & $\begin{array}{c}0.153^{* *} \\
(0.067) \\
\end{array}$ & $\begin{array}{r}-0.161^{*} \\
(0.084) \\
\end{array}$ & 122 \\
\hline \multicolumn{4}{|c|}{ Panel B: Common Slope from Panel Regressions } \\
\hline All categories (sectoral weights) & $\begin{array}{c}-0.166^{* * *} \\
(0.043)\end{array}$ & $\begin{array}{l}0.268^{* * *} \\
(0.096)\end{array}$ & 1,780 \\
\hline All categories (equal weights) & $\begin{array}{c}-0.156^{* * *} \\
(0.060)\end{array}$ & $\begin{array}{l}0.342^{* *} \\
(0.143)\end{array}$ & 1,780 \\
\hline All categories except fuel (sectoral weights) & $\begin{array}{c}-0.069^{* * *} \\
(0.017)\end{array}$ & $\begin{array}{l}0.095^{* * *} \\
(0.024)\end{array}$ & 1,536 \\
\hline Core categories only (sectoral weights) & $\begin{array}{c}-0.054^{* * *} \\
(0.018)\end{array}$ & $\begin{array}{l}0.070^{* * * *} \\
(0.023)\end{array}$ & 1,292 \\
\hline
\end{tabular}

Source: Authors' calculations.

Notes: The table shows the unemployment gap coefficient before the break (defined as 2010q3) and the change in this coefficient after the break obtained from time-series regressions estimated separately for each sector (Panel A) and in a panel of sectors (Panel B). A positive change indicates a Phillips curve flattening. Sample period: 1986q1-2017q3. Dependent variable: change in the quarterly seasonally adjusted sectoral CPI from the previous year. Controls: five lags of the dependent variable and the percentage change in the price of oil. Newey-West standard errors in parentheses. ${ }^{* * *},{ }^{* *}$, and ${ }^{*}$ represent 1 percent, 5 percent, and 10 percent significance levels, respectively.

parameters are sector specific. Panel B of Figure 3 shows $p$-values for the test that $\widetilde{\beta}_{j}=0$. The null hypothesis that the slope is the same before and after the break is rejected at the 1 percent significance level in three sectors: "Food Away from Home," "Owners' Equivalent Rent," and "Rent of Primary Residence." The break in "New and Used Vehicles" is significant at the 10 percent level, but many categories are very close to the threshold, suggesting that some changes took place across the board. ${ }^{9}$

\footnotetext{
${ }^{9}$ Note that the estimation of the structural break is robust to excluding owners' imputed rents (or all housing compo-
} 
Figure 4. Disaggregated Inflation Rates: Changing Dynamics

Source: BLS.

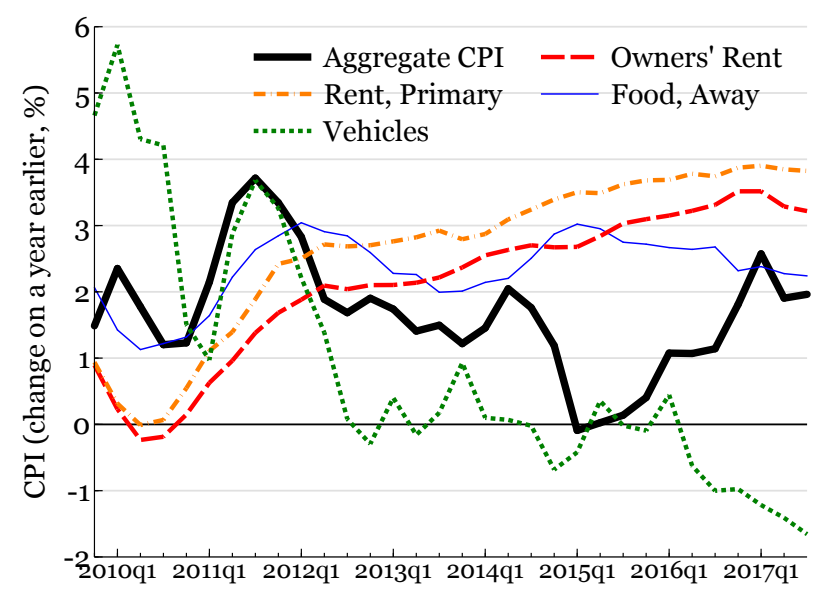

Notes: This figure presents inflation dynamics in product categories with a structural break around 2010q3.

We reach this conclusion also when we look at individual slopes before the break $\beta_{j}$ and at the difference in slopes before and after the break $\widetilde{\beta}_{j}$ (Panel A of Table 2 ). In most cases, $\widetilde{\beta}_{j}>0$, and often $\widetilde{\beta}_{j} \approx-\beta_{j}$. These estimates indicate a flattening of the Phillips curve after the Great Recession to essentially a horizontal line (that is, inflation does not respond to the unemployment gap). One exception is "New and Used Vehicles," for which inflation became more procyclical. Panel B of Table 2 compares these sectoral coefficients to those from the panel regression in Equation (1) that were obtained with and without sectoral weights. It also excludes volatile fuel and food prices. The two approaches paint a consistent picture of a flattening Phillips curve.

Figure 4 focuses on the four categories with a statistically significant structural break. Three of them had inflation rates above 2 percent in 2017q3. Rent growth steadily increased from between 2 percent and 2.5 percent at the beginning of 2012 to between 3 percent and 4 percent at the end of 2017. "Food Away from Home" inflation declined during 2016-2017. "New and Used Vehicles" inflation fell and was in negative territory, which is consistent with the negative change in its slope. The flattening of the Phillips curve for rents and restaurant food indicates that inflation in these categories would have risen more drastically had the slope change not occurred.

In Figure 5, we use estimates from Table 2 and actual unemployment gap dynamics to estimate what sectoral and aggregate inflation would be if the Phillips curve flattening had not occurred. Between 2010q3 (the break point) and 2017q3, the unemployment gap decreased from 4.4 percentage points to -0.4 percentage points. Based on our panel estimates, without slope changes, headline CPI inflation would be 1.29 percentage points above the actual level. A different aggregation method that first predicts inflation in each sector from sector-specific regressions and then aggregates sectoral rates using CPI weights produces a more modest estimate of 0.73 percentagepoint-higher inflation. The contribution of the three sectors with a statistically significant flattening is 0.49 percentage points, or about two-thirds of the difference between actual CPI inflation and the counterfactual estimate.

nents) from the panel estimations used to identify a break (Panel F of Appendix Figure A4). 
Figure 5. How Much Higher Sectoral Inflation Would Be without a Phillips Curve Flattening?

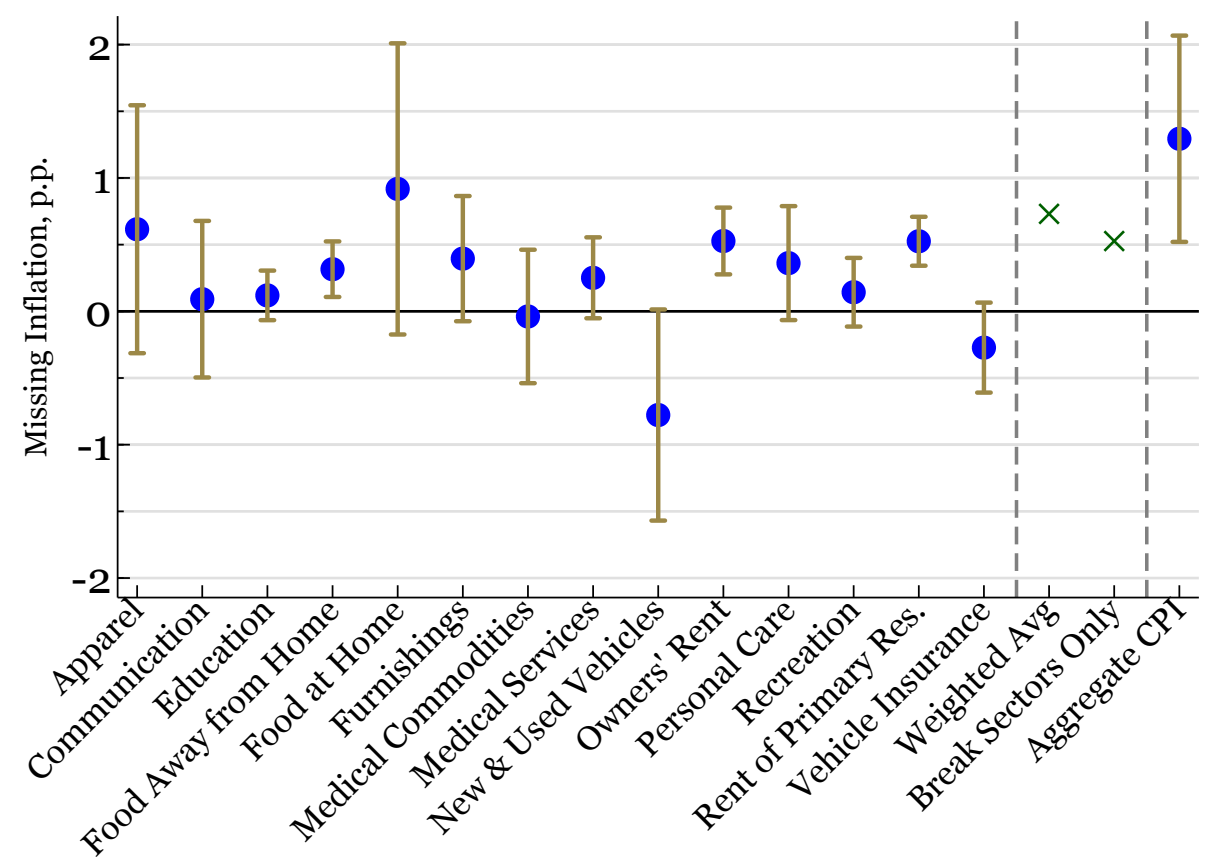

Source: Authors' calculations.

Notes: Blue dots show a missing increase in current (2017q3) sectoral inflation due to a Phillips curve flattening, calculated based on sectoral Phillips curves using time-series (all but the last dot) and panel (last dot for aggregate CPI) analyses, and the bars represent the corresponding 95 percent confidence bands. The $\times$ mark is for the weighted average of sectoral inflation rates with current CPI weights. The panel and weighted average estimates also include "Motor Fuel" (Transportation) and "Fuels and Utilities" (Housing), which were dropped from the graph for visibility. "Break Sectors Only" include "Food Away from Home," "Owners' Rent," and "Rent of Primary Residence."

We next examine changes in the reduced-formed persistence of sectoral inflation, followed by a structural interpretation of our reduced-form estimates.

\section{Sectoral Inflation Persistence and Forward-Looking Expectations}

The reduced-form version of the sectoral Phillips curve has an important omission: inflation expectations. At the aggregate level, the reduced-form equation can be augmented with survey measures such as consumer expectations from the Michigan survey or expectations from the Survey of Professional Forecasters (SPF). However, no measure of sectoral inflation expectations exists. Everything else being equal, a change in the relative weights of forward-looking and backward-looking inflation expectation components should be tightly linked to a change in unconditional inflation persistence. $^{10}$

To shed light on these issues, we first look at the persistence of the sectoral inflation process in each sector. Looking at unconditional persistence provides the advantage of not having to rely on the assumptions of a particular model. This approach also has a long tradition in the literature. For example, Fuhrer (2010) documents a decline in inflation persistence during the Great Moderation.

\footnotetext{
${ }^{10}$ Unconditional inflation persistence can also change because of persistence changes in the inherited processes: the unemployment gap and cost-push shocks.
} 
Table 3. Sectoral Inflation Persistence: Sum of Autoregressive Coefficients

\begin{tabular}{lccc}
\hline \hline Sector & Full sample & '86q1-'09q3 & '09q4-'17q3 \\
& $(1)$ & $(2)$ & $(3)$ \\
\hline Apparel & 0.935 & 0.951 & 0.851 \\
& $(0.037)$ & $(0.040)$ & $(0.108)$ \\
Education & 1.014 & 0.947 & 0.963 \\
& $(0.023)$ & $(0.046)$ & $(0.055)$ \\
Communication & 0.901 & 0.922 & 0.973 \\
& $(0.077)$ & $(0.111)$ & $(0.130)$ \\
Recreation & 0.896 & 0.906 & 0.552 \\
& $(0.044)$ & $(0.062)$ & $(0.133)$ \\
Food Away from Home & 0.935 & 0.950 & 0.456 \\
& $(0.024)$ & $(0.026)$ & $(0.086)$ \\
Food at Home & 0.862 & 0.834 & 0.797 \\
& $(0.050)$ & $(0.065)$ & $(0.092)$ \\
Fuels and Utilities & 0.789 & 0.780 & 0.653 \\
& $(0.060)$ & $(0.073)$ & $(0.153)$ \\
Household Furnishings and Operations & 0.934 & 0.923 & 0.536 \\
& $(0.034)$ & $(0.047)$ & $(0.134)$ \\
Owners' Equivalent Rent & 0.957 & 0.943 & 0.963 \\
& $(0.022)$ & $(0.036)$ & $(0.032)$ \\
Rent of Primary Residence & 0.935 & 0.911 & 0.962 \\
& $(0.022)$ & $(0.032)$ & $(0.038)$ \\
Medical Commodities & 0.965 & 0.972 & 0.747 \\
& $(0.021)$ & $(0.022)$ & $(0.133)$ \\
Medical Services & 0.981 & 0.979 & 0.597 \\
& $(0.017)$ & $(0.019)$ & $(0.150)$ \\
Personal Care & 0.919 & 0.806 & 0.641 \\
& $(0.053)$ & $(0.137)$ & $(0.149)$ \\
Motor Fuel & 0.684 & 0.594 & 0.795 \\
Vehicle Insurance & $(0.086)$ & $(0.115)$ & $(0.138)$ \\
New and Used Vehicles & 0.954 & 0.954 & 1.070 \\
& $(0.022)$ & $(0.023)$ & $(0.104)$ \\
\hline & 0.918 & 0.926 & 0.871 \\
& $(0.038)$ & $(0.039)$ & $(0.123)$ \\
\hline
\end{tabular}

Source: Authors' calculations.

Notes: The table presents the sum of autoregressive coefficients from an estimated AR(5) process. All coefficients are statistically different from zero at the 1 percent level.

Such a decline can be explained by, among other factors, the anchoring of inflation expectations. We find evidence of a decline in inflation persistence at the sectoral level during and after the Great Recession (Table 3). ${ }^{11}$ The change occurred across the board but more so in "Medical Services," "Recreation," "Food Away from Home," and "Household Furnishings and Operations." Part of the story, however, could be persistence inherited from sectoral shocks.

To differentiate between intrinsic and inherited inflation persistence, we need theory that disciplines structural parameters. Byrne, Kontonikas, and Montagnoli (2013) provide one solution: the reduced-form Equation (1) can be derived from a hybrid New Keynesian Phillips curve (NKPC), and one can retrieve the coefficients of the model using a stationary rational expectations (RE) solution. To solve for such an equilibrium, we need to impose stationarity on the driving variable (the unemployment gap). To illustrate this principle, let us assume that the driving variable follows a stationary AR(1) process (that is, the unemployment gap persistence is less than unity).

\footnotetext{
${ }^{11}$ In Section 3, we identified a structural break in the slope of the Phillips curve $\beta$ in 2010q3. However, the $F$-test used to select the date was elevated throughout the Great Recession. Since we split the sample into two periods for the analysis in this section, we start the second period earlier, in 2009q3, to gain a few observations. This slight inconsistency does not affect our conclusions.
} 
Combining the unemployment gap process with the hybrid NKPC leads to the following model:

$$
\begin{aligned}
\pi_{j t} & =\lambda_{j}^{b} \pi_{j, t-1}+\lambda_{j}^{f} \mathbb{E}_{t} \pi_{j, t+1}+\theta_{j} u_{t}+e_{j t}, \\
u_{t} & =\rho^{u} u_{t-1}+\eta_{t},
\end{aligned}
$$

where $\lambda_{j}^{b}$ and $\lambda_{j}^{f}$ are the relative weights of the backward-looking and forward-looking expectation components (such that $\lambda_{j}^{b}+\lambda_{j}^{f}=1$ ), $\theta_{j}$ is the slope of the hybrid NKPC, and $\rho^{u}$ is the persistence of the unemployment gap. ${ }^{12}$ The stationary RE solution of this model is

$$
\pi_{j t}=\mu_{j}+\rho_{j}^{\pi} \pi_{j, t-1}+\beta_{j} u_{t}+\varepsilon_{j t}
$$

where the parameters are related as follows:

$$
\begin{aligned}
\lambda_{j}^{b} & =\frac{\rho_{j}^{\pi}}{1+\rho_{j}^{\pi}}, \\
\lambda_{j}^{f} & =\frac{1}{1+\rho_{j}^{\pi}}, \\
\theta_{j} & =\beta_{j}\left(1-\rho^{u}\right)\left(1-\lambda_{j}^{b}\right) .
\end{aligned}
$$

The parameters governing the relative weights of the backward-looking and forward-looking expectations components $\left(\lambda_{j}^{b}, \lambda_{j}^{f}\right)$ depend only on parameters from the reduced-form Phillips curve and do not require estimating the process on the driving variable. ${ }^{13}$ In contrast, estimates of the structural slope $\theta_{j}$ also depend on the unemployment gap persistence. The model requires stationarity of the unemployment gap, but in the data the gap is a highly persistent process, with persistence coefficients as high as 0.97 . Such a high persistence drives the slope very close to zero. However, the coefficient can be sizable even if the gap is highly persistent (for example, if $\rho^{u}=0.7$ ). Given this uncertainty, we focus on $\lambda_{j}^{b}$, which mechanically also informs us about $\lambda_{j}^{f}=1-\lambda_{j}^{b}$.

We aggregate $\lambda_{j}^{b}$ using a weighted mean group estimator (Pesaran and Smith 1995, Pesaran 2006). The mean group estimates and their standard errors can be computed as

$$
\begin{gathered}
\hat{\lambda}_{\mathrm{MG}}^{b}=\sum_{j=1}^{N} w_{j} \hat{\lambda}_{j}^{b}, \\
\operatorname{Std.Err.}\left(\hat{\lambda}_{\mathrm{MG}}^{b}\right)=\sqrt{\frac{1}{N-1} \sum_{j=1}^{N} w_{j}\left(\hat{\lambda}_{j}^{b}-\hat{\lambda}_{\mathrm{MG}}^{b}\right)^{2},}
\end{gathered}
$$

\footnotetext{
${ }^{12}$ Imbs, Jondeau, and Pelgrin (2011), Byrne, Kontonikas, and Montagnoli (2013), and others use sectoral marginal cost as the driving variable, allowing it to vary across $j$. Since we use the unemployment gap instead and data on sectoral unemployment are limited, we deviate from this practice and use a sector-invariant measure, $u_{t}$.

${ }^{13}$ The parameters $\rho^{u}, \beta_{j}$, and $\rho_{j}^{\pi}$ can be estimated jointly using full information maximum likelihood (FIML). However, since $\lambda_{j}^{b}$ and $\lambda_{j}^{f}$ do not depend on $\rho^{u}$, they can be recovered by estimating Equation (4) separately. Empirically, reducedform and FIML estimates point to mostly similar conclusions.
} 
Table 4. Intrinsic Inflation Persistence: Backward- vs. Forward-Looking Expectations in Hybrid NKPC

\begin{tabular}{|c|c|c|c|}
\hline Sector & $\begin{array}{c}\text { Full sample } \\
\text { (1) }\end{array}$ & $\begin{array}{c}\text { '86q1-'09q3 } \\
\text { (2) }\end{array}$ & $\begin{array}{c}\text { '09q4-'17q3 } \\
\text { (3) }\end{array}$ \\
\hline \multicolumn{4}{|c|}{ Panel A: Mean-Group Aggregate Estimates, $\hat{\lambda}_{\mathrm{MG}}^{b}$} \\
\hline All categories & $\begin{array}{l}0.464^{* * *} \\
(0.006)\end{array}$ & $\begin{array}{l}0.469^{* * *} \\
(0.008)\end{array}$ & $\begin{array}{l}0.386^{* * *} \\
(0.015)\end{array}$ \\
\hline All categories except fuel & $\begin{array}{l}0.468^{* * *} \\
(0.005)\end{array}$ & $\begin{array}{l}0.475^{* * *} \\
(0.006)\end{array}$ & $\begin{array}{l}0.388^{* * *} \\
(0.016)\end{array}$ \\
\hline Core categories only & $\begin{array}{l}0.473^{* * *} \\
(0.004)\end{array}$ & $\begin{array}{l}0.481^{* * *} \\
(0.003)\end{array}$ & $\begin{array}{l}0.390^{* * * *} \\
(0.019)\end{array}$ \\
\hline \multicolumn{4}{|c|}{ Panel B: Sectoral Weight of Backward-Looking Expectations, $\hat{\lambda}_{j}^{b}$} \\
\hline Owners' Equivalent Rent & 0.470 & 0.481 & 0.435 \\
\hline Rent of Primary Residence & 0.460 & 0.469 & 0.331 \\
\hline Food at Home & 0.422 & 0.417 & 0.394 \\
\hline Medical Services & 0.494 & 0.504 & 0.272 \\
\hline New and Used Vehicles & 0.471 & 0.480 & 0.450 \\
\hline Food Away from Home & 0.474 & 0.481 & 0.350 \\
\hline Recreation & 0.460 & 0.472 & 0.346 \\
\hline Fuels and Utilities & 0.437 & 0.444 & 0.317 \\
\hline Household Furnishings and Operations & 0.464 & 0.460 & 0.330 \\
\hline Communication & 0.480 & 0.494 & 0.395 \\
\hline Motor Fuel & 0.398 & 0.356 & 0.437 \\
\hline Education & 0.504 & 0.493 & 0.492 \\
\hline Apparel & 0.466 & 0.476 & 0.334 \\
\hline Vehicle Insurance & 0.488 & 0.486 & 0.452 \\
\hline Personal Care & 0.465 & 0.466 & 0.330 \\
\hline Medical Commodities & 0.491 & 0.495 & 0.422 \\
\hline
\end{tabular}

Source: Authors' calculations.

Notes: Panel A presents mean group estimates (with sectoral weights) of the relative weight of the backward-looking expectation component in the hybrid NKPC described in Equation (2). Panel B presents coefficients by sector. The estimated regression includes five lags of sectoral inflation, the contemporaneous change in the oil price, and consumer inflation expectations from the Michigan survey. Rows are ordered by sectoral weights. ${ }^{* *},{ }^{* *}$, and ${ }^{*}$ represent 1 percent, 5 percent, and 10 percent significance levels, respectively.

where $w_{j}$ are sectoral weights. ${ }^{14}$

To summarize, our algorithm works as follows:

1. Estimate $\rho_{j}^{\pi}$ from Equation (4) for each $j ;^{15}$

2. Compute $\lambda_{j}^{b}$ using the mapping from Equations (5);

3. Obtain the mean group estimate $\hat{\lambda}_{\mathrm{MG}}^{b}$ and its standard error from Equations (6).

Panel A of Table 4 presents the mean group estimate of the backward-looking component weight $\left(\lambda^{b}\right)$ in the hybrid NKPC for the entire sample period, as well as for two subsamples split around the Great Recession (2009q3). The weight of the backward-looking (forward-looking) component is lower (higher) after the Great Recession. This result also holds for core sectors. Panel B of Table 4 shows that an increase (decrease) in the weight of the forward-looking (backward-looking) component is observed in many sectors, which is consistent with the univariate sectoral analysis. In summary, it appears that intrinsic inflation persistence has declined.

\footnotetext{
${ }^{14}$ Our conclusions also hold with equal weights.

${ }^{15}$ In practice, we allow for five lags of sectoral inflation and compute $\rho_{j}^{\pi}$ as the sum of autoregressive coefficients. We also include additional controls such as the percentage change in the oil price.
} 


\section{Concluding Remarks}

Using disaggregated CPI data, we document a significant change in the Phillips curve slope around 2009-2010. The flattening of the curve is present in a wide range of consumer categories. However, it is worth paying special attention to housing and services such as food away from home, because these sectors contributed the most to the break in a statistical sense. Such categories did not necessarily experience a significant technological revolution, nor were they affected by global trends in prices for tradeable goods. Other sector-specific explanations could be a promising subject of future research.

We also find that sectoral inflation became more (less) forward-looking (backward-looking) after the end of the Great Recession. The decline in inflation persistence is documented using both a simple time-series analysis at the sectoral level and a hybrid New Keynesian Phillips curve model.

Further research is needed to determine why inflation became more forward-looking. Perhaps consistently low inflation led to a diminishing role of indexation, or changes in Federal Reserve communication strategies made markets pay more attention to future policies than to past realizations of macroeconomic variables. Changes in market competition, inequality, and the role of technological progress are worth exploring. Whatever the reason, a decrease in inflation persistence implies that low inflation today may not necessarily signal low inflation tomorrow. 


\section{Appendix}

\section{A Additional Results}

Figure A1. Disaggregated Inflation Rates, All Level I Categories (incl. Transportation)

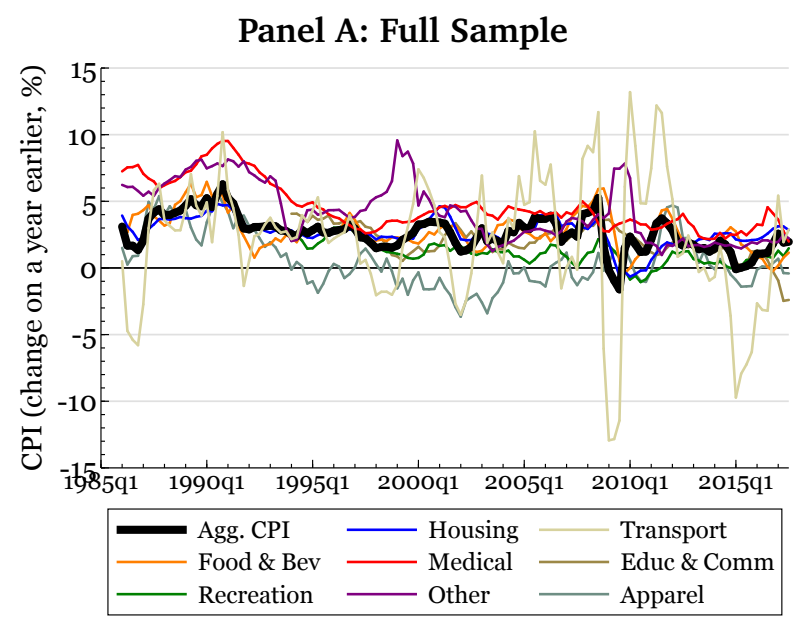

Panel B: Post-Great Recession Period

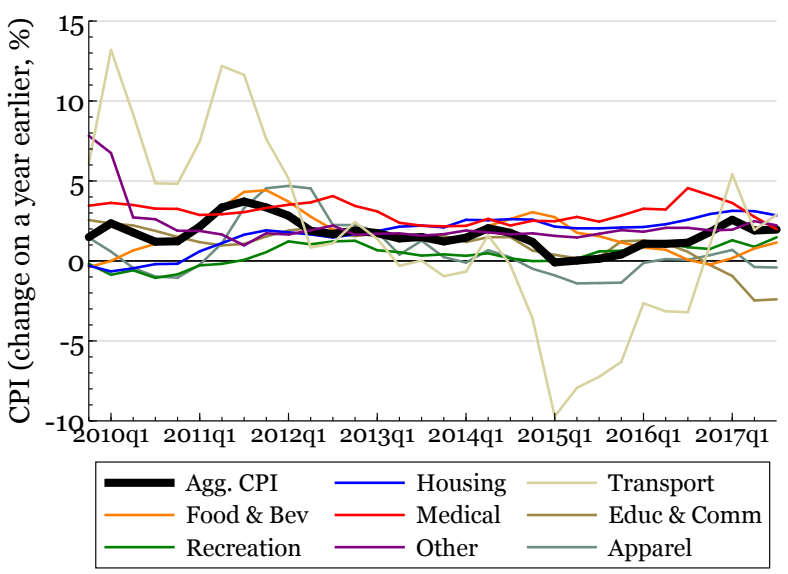

Source: BLS.

Figure A2. Panel Regression, F-statistic: Robustness Checks I

Panel A: No Energy Prices

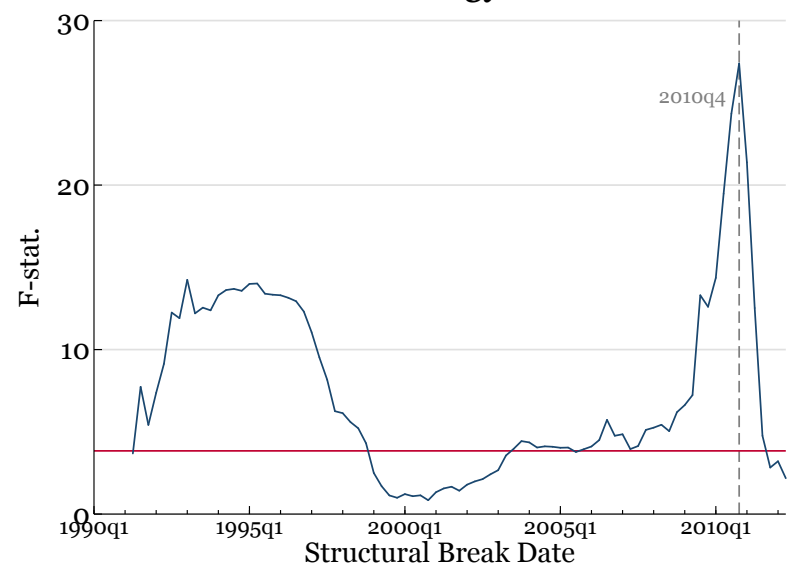

Panel B: Core Categories

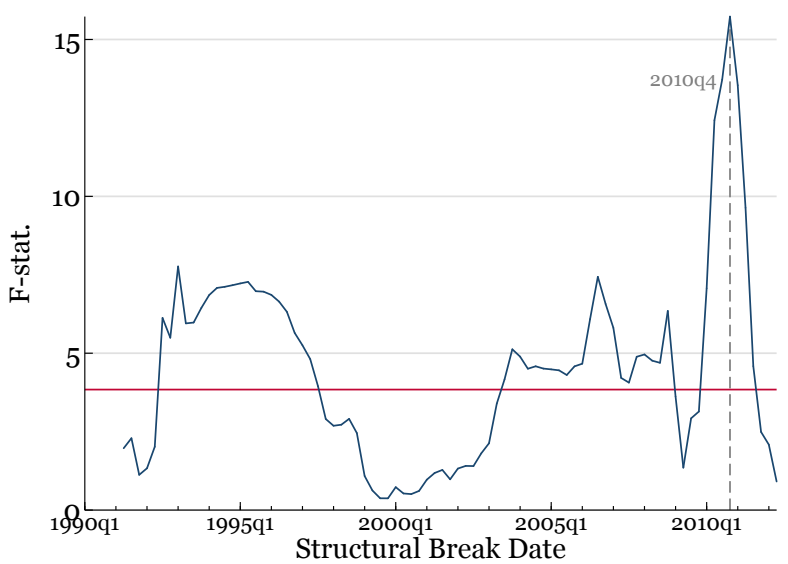

Source: Authors' calculations. 
Figure A3. Real-Time vs. Revised Data
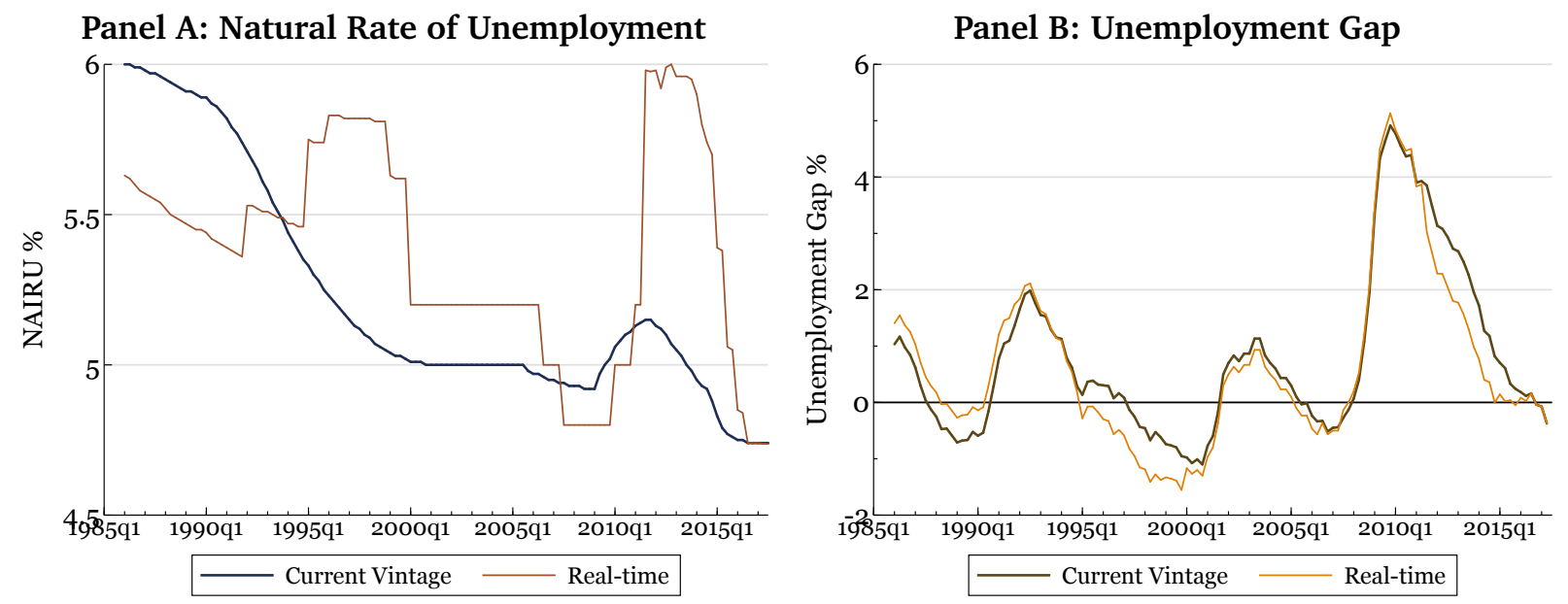

Source: BLS; CBO. 
Figure A4. Panel Regression, F-statistic: Robustness Checks II
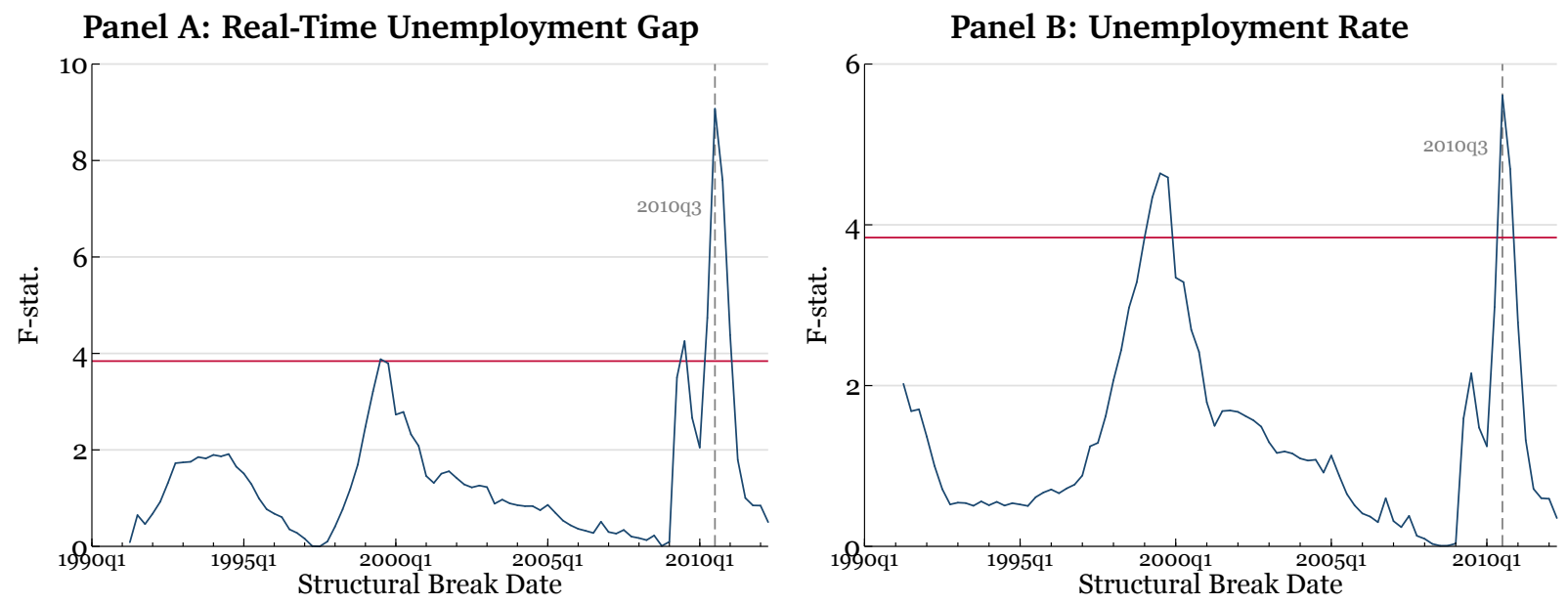

Panel C: Lags of Aggregate Inflation
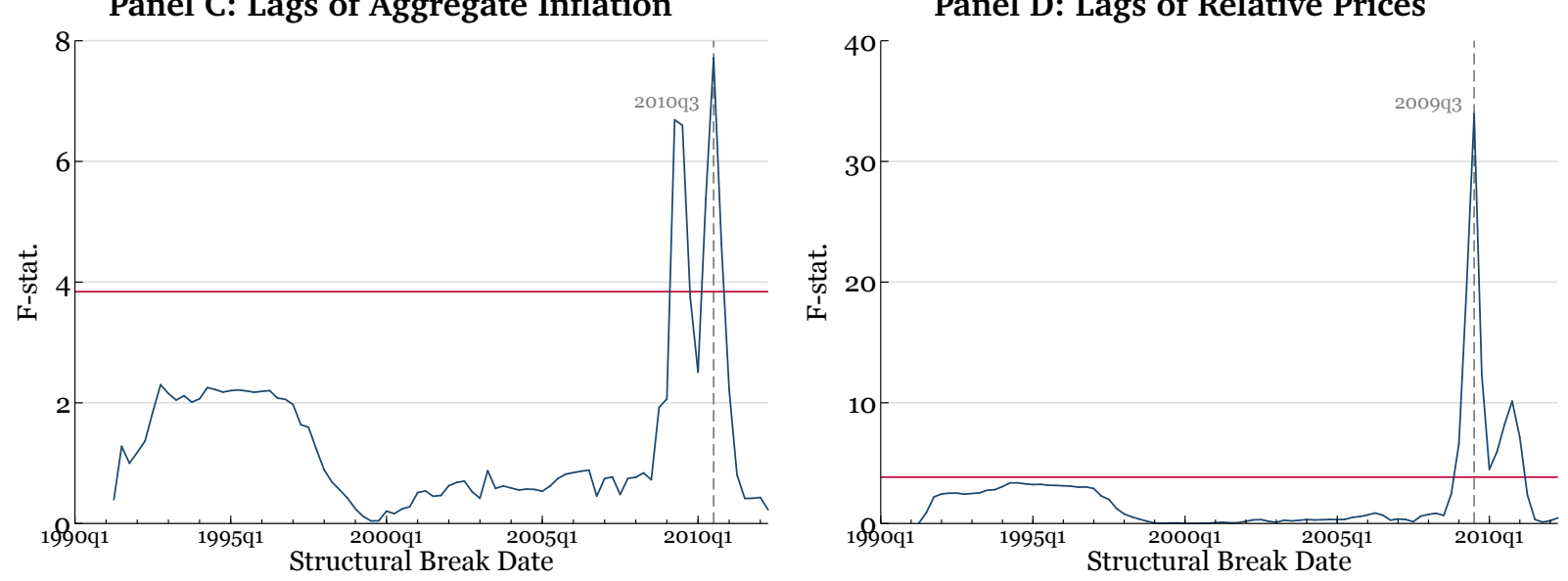

Panel E: Alternative Trimming (2 years)
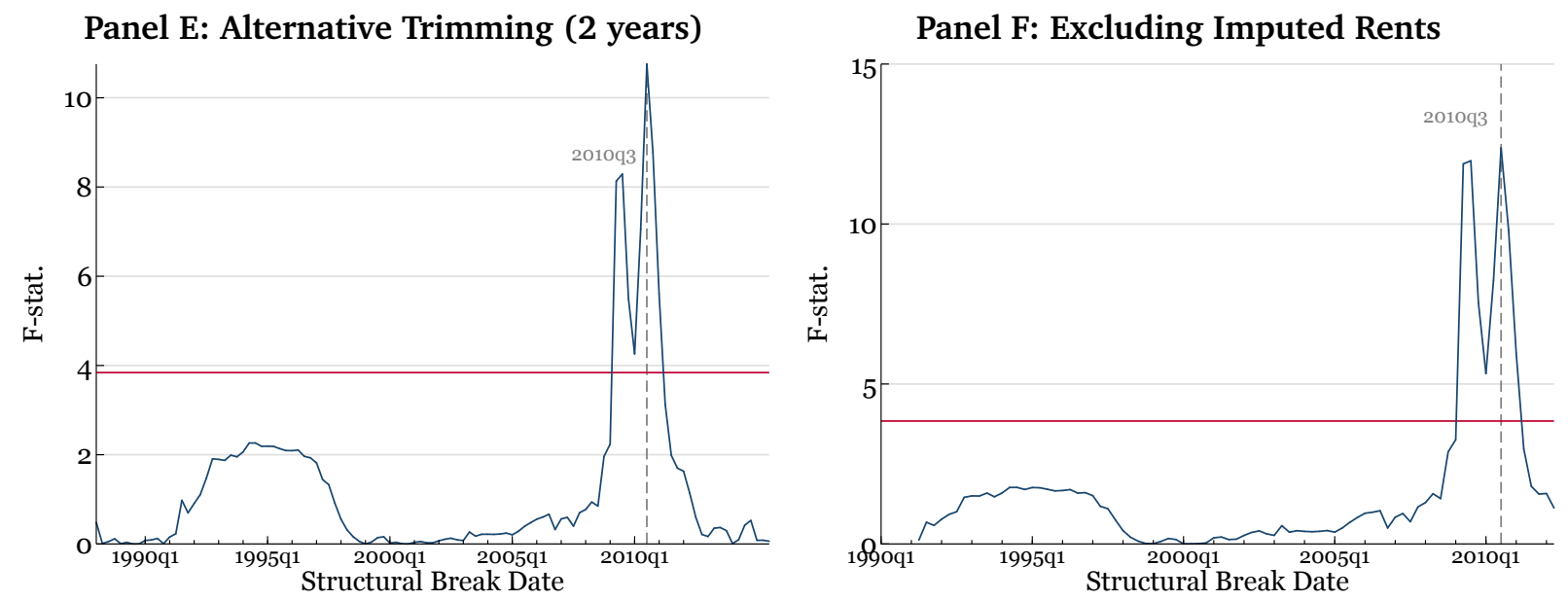

Source: Authors' calculations. 


\section{B Full List of Categories}

Table B1. Full List of Categories Used for Our Analysis

\begin{tabular}{lcc}
\hline \hline Housing & & \\
Owners' Equivalent Rent of Residences & $24.6 \%$ & Level III \\
$\quad$ Rent of Primary Residence & $7.9 \%$ & Level III \\
$\quad$ Fuels and Utilities & $5.0 \%$ & Level II \\
$\quad$ Level II \\
Household Furnishings and Operations & $4.0 \%$ & \\
Transportation & & Level III \\
$\quad$ New and Used Motor Vehicles & $6.4 \%$ & Level III \\
$\quad$ Motor Fuel & $3.3 \%$ & Level III \\
$\quad$ Motor Vehicle Insurance & $2.5 \%$ & \\
Food and Beverages & & Level III \\
$\quad$ Food at Home & $7.9 \%$ & Level III \\
Food Away from Home & $5.7 \%$ & \\
Medical Care & & Level II \\
$\quad$ Medical Care Services & $6.7 \%$ & Level II \\
$\quad$ Medical Care Commodities & $1.9 \%$ & \\
Education and Communication & & Level II \\
$\quad$ Communication & $3.8 \%$ & Level II \\
$\quad$ Education & $3.2 \%$ & Level I \\
Recreation & $5.7 \%$ & \\
Other Goods and Services & & Level II \\
$\quad$ Personal Care & $2.5 \%$ & Level I \\
Apparel & $3.0 \%$ & \\
\hline
\end{tabular}

Notes: The table presents the list of disaggregated CPI categories used in our analysis and their 2017 CPI weights. 


\section{References}

Byrne, Joseph P., Alexandros Kontonikas, and Alberto Montagnoli. 2013. "International Evidence on the New Keynesian Phillips Curve Using Aggregate and Disaggregate Data." Journal of Money, Credit and Banking 45(5): 913-932.

Coibion, Olivier, Yuriy Gorodnichenko, and Rupal Kamdar. 2017. "The Formation of Expectations, Inflation and the Phillips Curve." Journal of Economic Literature. Forthcoming.

Doser, Alexander, Ricardo Nunes, Nikhil Rao, and Viacheslav Sheremirov. 2017. "Inflation Expectations and Nonlinearities in the Phillips Curve." Federal Reserve Bank of Boston Working Paper 17-x.

Fuhrer, Jeffrey C. 2010. "Inflation Persistence." In Handbook of Monetary Economics, vol. 3, edited by Benjamin M. Friedman and Michael Woodford, chap. 9, pp. 423-486. Amsterdam: Elsevier.

Imbs, Jean, Eric Jondeau, and Florian Pelgrin. 2011. "Sectoral Phillips Curves and the Aggregate Phillips Curve." Journal of Monetary Economics 58(4): 328-344.

Miles, David, Ugo Panizza, Ricardo Reis, and Ángel Ubide. 2017. "And Yet It Moves: Inflation and the Great Recession." The 19th Geneva Report on the World Economy. International Center for Monetary and Banking Studies and Centre for Economic Policy Research. Available at voxeu.org/content/and-yet-itmoves-inflation-and-great-recession.

Pesaran, M. Hashem. 2006. "Estimation and Inference in Large Heterogeneous Panels with a Multifactor Error Structure.” Econometrica 74(4): 967-1012.

Pesaran, M. Hashem, and Ronald P. Smith. 1995. "Estimating Long-Run Relationships from Dynamic Heterogeneous Panels." Journal of Econometrics 68(1): 79-113.

Yellen, Janet L. 2017. "Inflation, Uncertainty, and Monetary Policy." Remarks at the "Prospects for Growth: Reassessing the Fundamentals." The 59th Annual Meeting of the National Association for Business Economics. Cleveland, OH, September 26, 2017. Available at federalreserve.gov/newsevents/speech/yellen20170926a.htm. 